\title{
Media Video Profile Sebagai Sarana Promosi StarHits Pada Suara Mas Abadi Jakarta
}

\author{
Ria Wulandari ${ }^{1}$, Mohamad Faisal Abdillah*2 ${ }^{2}$, Patric Bagas Agastya Adhi Putra ${ }^{3}$ \\ ${ }^{1,2,3}$ Program Studi Teknik Informatika, Fakultas Sains and Teknologi, Universitas Raharja \\ Email: ${ }^{1}$ wulandari@ raharja.info,${ }^{2}$ mohamad.faisal@ raharja.info, \\ ${ }^{3}$ patric.bagas@ raharja.info
}

\begin{abstract}
Abstrak
Penggunaan video profile sangat diminati untuk kebutuhan perusahaan, instansi dan lembaga pendidikan sebagai sarana promosinya, melalui media video profile ini dapat membantu StarHits dalam mempromosikan jasa layanan digital serta membantu para creator dan creator corporate dalam membuat sebuah konten yang akan didistribusikan melalui platform media sehingga memudahkan para creator dan creator corporate yang ingin bergabung dengan StarHits. Permasalahan yang dihadapi oleh StarHits dalam mempromosikan jasa layanan digital, yaitu hanya menggunakan media sosial seperti youtube, tiktok, facebook dan twitter yang berisikan tentang isi konten dari creator dan creator corporate, maka diperlukan media video profile untuk StarHits sebagai sarana promosinya. Tujuan penelitian ini yaitu untuk membantu marketing dalam menjelaskan ruang lingkup StarHits secara detail, agar mempersingkat pertemuan dengan calon creator. Penelitian ini menggunakan metode observasi, wawancara, studi pustaka dan konsep produksi media (KPM). Menggunakan software Adobe After Effects CC 2019, Adobe Premiere CC 2019, Adobe Ilustrator CC 2019, Adobe Media Encoder CC 2019. Yang dihasilkan berupa media video profile StarHits yang dapat membantu kegiatan promosi perusahaan, dan meningkatkan kerjasama dengan relasi.
\end{abstract}

Kata Kunci - Video profile, promosi, StarHits

\begin{abstract}
The use of video profiles is in great demand for the needs of companies, institutions and educational institutions as a means of promotion, through this video profile media can help StarHits in promoting digital services and assist creators and corporate creators in creating content that will be distributed through media platforms making it easier for creators and corporate creators who want to join StarHits. The problems faced by StarHits in promoting digital services, namely only using social media such as youtube, tiktok, facebook and twitter which contain content from creators and corporate creators, then a media video profile is needed for StarHits as a means of promotion. The purpose of this research is to assist marketing in explaining the scope of StarHits in detail, in order to shorten the meeting with potential creators. This study uses the method of observation, interviews, literature study and the concept of media production (KPM). Using Adobe After Effects CC 2019 software, Adobe Premiere CC 2019, Adobe Illustrator CC 2019, Adobe Media Encoder CC 2019. The result is a StarHits video profile media that can help company promotional activities, and increase collaboration with relationships.
\end{abstract}

Keywords - Profile video, promotion, StarHits

\section{PENDAHULUAN}

Saat ini perkembangan zaman teknologi semakin meningkat khsususnya dalam bidang multimedia audio visual salah satunya yaitu media video profile. Media video profile sangat diminati dan dibutuhkan oleh sebuah perusahaan, instansi maupun lembaga pendidikan untuk dijadikan sebagai strategi penunjang promosi dan informasi. Maka video profile sangatlah 
berperan penting untuk membangun sebuah citra perusahaan, instansi maupun lembaga pendidikan agar dapat dikenal oleh khalayak luas.

Video Profile adalah video yang dibuat berisi profil yang menggambarkan bagaimana umumnya mengenai profil sendiri dari perusahaan tersebut ${ }^{[1]}$.

Promosi merupakan salah satu bagian dari rangkaian kegiatan pemasaran suatu barang ${ }^{[2] .}$

StarHits merupakan perusahaan media digital, yang menyediakan layanan dalam hal pembuatan, pendistribusian, pengelola, monetisasi konten, dengan menjalankan produksi, dan mengelola distribusi video. Berdasarkan BPS jumlah penduduk yang sudah memiliki KTP di Jakarta Barat pada tahun 2020 yaitu berjumlah 2,222,828. juta jiwa, yang memiliki penduduk terbanyak kedua setelah Jakarta Timur, sehingga masih banyak peluang bagi StarHits untuk mendapatkan creator dan creator corporate yang lebih banyak lagi.

Permasalahan yang dihadapi oleh StarHits yaitu saat ini belum memiliki media Video profile sebagai sarana penunjang promosinya. Sebelumnya hanya menggunakan sarana media sosial seperti youtube, tiktok, facebook dan twitter, yang berisikan tentang highlight isi konten dari creator dan creator corporate yang sudah bergabung, acara-acara yang sedang berjalan dan untuk website berisi tentang our business dan creator siapa saja yang sudah bergabung dengan StarHits, hingga melakukan presentasi secara langsung kepada creator sebagai sarana promosi.

Maka diperlukan media video profile dengan menyampaikan keseluruhan ruang lingkup perusahaan kepada publik dengan informasi yang akurat serta memudahkan para creator dan creator corporate yang ingin bergabung dengan StarHits.

Tujuan adanya media video profile ini adalah untuk membantu dalam mempromosikan jasa layanan digital serta membantu para creator dan creator corporate dalam membuat serta mengelola konten, yang nantinya akan didistribusikan secara efektif di seluruh platform media, untuk meningkatkan jangkauan audiens atau penjualan.

Melalui media Video profile ini, dapat membantu perusahaan dalam pemasaran jasanya, serta dapat membantu creator dan creator corporate untuk mengetahui profil serta layanan digital pada StarHits.

\section{METODE PENELITIAN}

Metode penelitian yang digunakan yaitu: (1) Pengumpulan Data, meliputi Observasi, Interview (Wawancara) dan Studi pustaka. (2) Video profile ini dirancang dengan menggunakan software Adobe Premiere CC 2019, Adobe Ilustrator CC 2019, Adobe Media Encoder CC 2019 dan Adobe After Effect CC 2019. (3) Tahapan Konsep Produksi Media (KPM) meliputi: Pre Production, Production dan Post Production.

\section{Literature Review}

1. Penelitian yang dilaksanakan Hidayat, dkk (2019) "Pembuatan Video Profile Perusahaan Berbasis Animasi 3D di PT. Krakatau Insan Mandiri". Penelitian ini untuk memperkenalkan perusahaan yang bergerak di bidang suplier sehingga konsumen dapat memahami dengan jelas. ${ }^{[3]}$

2. Penelitian yang dilaksanakan oleh Jasmine dan Redito Benaya Loen (2020) "Penggunaan Video Company Profile Sebagai Sarana Informasi dan Meningkatkan Promosi Pada PT. Avoir Industry". Video company profile ini untuk memberikan 
promosi dan informasi mengenai PT. Avoir Industry agar lebih dikenal oleh masyarakat. ${ }^{[4]}$

3. Penelitian yang dilaksanakan oleh Wibowo dan Jerremy Alexander (2021)"Perancangan dan Pembuatan Video Company Profile PT. Batam Indonesia Gemilang”. Tujuan dilaksanakan nya penelitian ini yaitu untuk membantu usaha PT. Batam Indonesia Gemilang. ${ }^{[5]}$

4. Penelitian yang dilaksanakan oleh Rustiana, dkk (2018) "Video Profile Contact Center 121 Pada PT. KAI (PERSERO)". Tujuan dilaksanakan nya penelitian ini yaitu untuk memberikan informasi dan memperkenalkan PT. Kereta Api Indonesia (PERSERO). ${ }^{6]}$

5. Penelitian yang dilaksanakan oleh Pratama dan Artyasto Jatisidi (2020) "Perancangan Video Company Profile PT. Dian Permata Omega Sebagai Media Promosi”. Tujuan dilaksanakan nya penelitian ini yaitu untuk membantu proses promosi yang dilakukan oleh PT. Dian Permata Omega. ${ }^{[7]}$

\section{HASIL DAN PEMBAHASAN}

\subsection{Preproduction}

Pre Production merupakan tahap-tahap dalam membuat sebuah ide yang bekerjasama untuk memproduksi gambar sesuai dengan storyboard: Berikut ini adalah sepuluh langkah dalam tahap pre production meliputi: Ide/Gagasan, Sinopsis/Cerita, Narasi, Storyboard, Script Wiriting, Rundown, Crew, Time Schedule, Budget / biaya yang dibutuhkan, dan Peralatan yang digunakan.

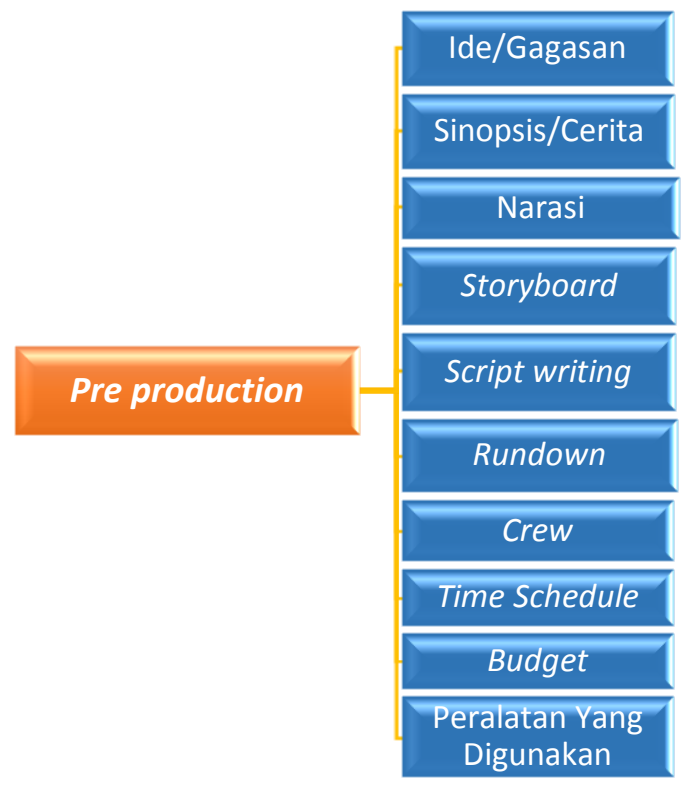

1. Ide/Gagasan

Gambar 1. Pre production

Rencana awal dalam proses pre production. Konsep yang dibutuhkan untuk membuat sebuah media video profile sebagai penunjang informasi dan promosi pada StarHits Jakarta yang menampilkan informasinya meliputi: Logo Perusahaan, Platform social media StarHits, Studio StarHits, Creator Unit MNC, Portofolio StarHits, Footage StarHits, Bumper Penutup.

2. Sinopsis atau Cerita

Sinopsis merupakan ringkasan dari cerita atau film sehingga dibentuk menjadi singkat, jelas dan padat. Sinopsis dari media video profile pada StarHits Jakarta adalah sebagai berikut : 
"Menampilkan bumper StarHits, Menampilkan footage Pintu masuk MNC Studio (Tower 1 dan Tower 3), Menampilkan footage Gedung Tower 1, Menampilkan footage Studio StarHits, Menampilkan footage Plang MNC Studio dan Gedung Tower 1, Menampilkan footage Plang StarHits, Menampilkan footage Studio StarHits, Menampilkan footage orang depan computer, Menampilkan animasi teks "4 main pillars for creator", Menampilkan Animasi tentang Service (Berisi tentang Optimization, Distribution, Protection, Monetization), Menampilkan animasi teks "Our Tools for Supporting Creator”, Menampilkan Animasi tentang Benefit (Berisi tentang Audio Library \& Visual Supporting, Article Publishing, CTR Optimize, Cross Promotion Playlist, Platform Connect, Studio Shooting, Collaboration, Reporting), Menampilkan Platform sosial media StarHits, Menampilkan Logo Social media Youtube, Menampilkan Logo Social media Instagram, Menampilkan Logo Social Media Facebook, Menampilkan Logo Social Media Tiktok, Menampilkan Logo Social Media Twitter, Menampilkan achievement StarHits, Menampilkan foto silver play button, Menampilkan achievement (Text Partner Official Facebook, Youtube, Twitter dan Tiktok), Menampilkan animasi achievement (logo pooping Facebook, Youtube, Twitter dan Tiktok), Menampilkan animasi achievement (slide highlight video Tiara Andini, Ziva Magnolya, Lyodra Ginting), Menampilkan Animasi creator (Arnold Poernomo, Capt.Vincent, Boy William, Tiara Andini, Jerome Polin, Gritte Agatha), Menampilkan Animasi creator unit MNC (GTV, INEWS, RCTI, MNCTV, Mop Channel, Mop Music), Menampilkan Animasi Portofolio StarHits (Youtube Music Night, StarHits Boost Holiday Special, Konser kebersamaan), Menampilkan Text Join Us (Email: StarHits@mncgroup.com, Website: https://starhits.id, Phone: (+62)21 5366-1736, Menampilkan Bumper penutup StarHits".

\section{Narasi}

Narasi adalah bentuk karangan cerita dari sebuah peristiwa yang terjadi. Berikut ini adalah sebuah narasi yg ada pada video profile sebagai sarana promosi pada StarHits Jakarta:

"Berdiri sejak tahun 2017/StarHits merupakan bisnis media digital yang bernaung di bawah Star Media Nusantaral yang dimana perusahaan tersebut adalah talent management terbesar di indonesia yang termasuk bagian dari MNC Group// StarHits sendiri merupakan perusahan Multi Channel Network yang menyediakan layanan dalam menciptakan/ mendistribusikan/ mengelola/ hingga memonetisasi konten// Inilah yang bisa kalian dapat saat bergabung dengan Starhits// yaitu service yang memiliki empat point berupa/Optimazation/Protection/Distribution/dan Monetization/ serta terdapat benefit yang terdiri dari Audio Library and Visual Supporting / Article Publishing / C.T.R Optimize / Cross Promotion Playlist / Platform Connect/ Studio Shooting / Collaboration / Reporting // StarHits juga memiliki lima sosial media yang sudah terverifikasi/ seperti/ Youtube/ Instagram/facebook/Tiktok/ dan twitter//

4. Storyboard

Storyboard merupakan urutan gambar berupa sketsa pensil dari jalannya sebuah cerita yang terjadi dalam setiap adegan.

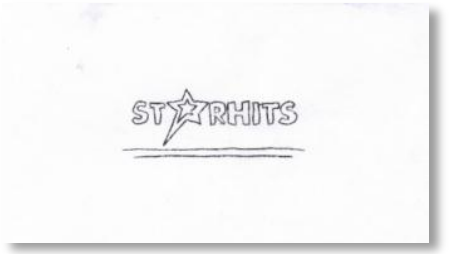

Gambar 2. Scene 1/ Bumper logo StarHits

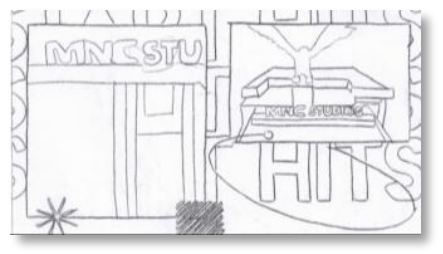

Gambar 3. Scene 2/ Ext/ Day / Eye level drone/ Menampilkan footage Pintu masuk MNC Studio (Patung Burung dan Tower 3) 


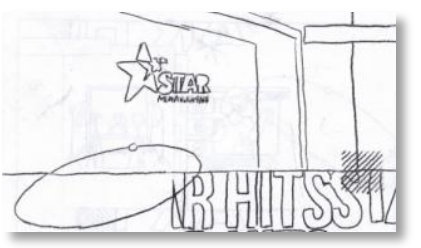

Gambar 4. Scene 3/ Int/ Day/ Long Shot/ Plang Star Media Nusantara

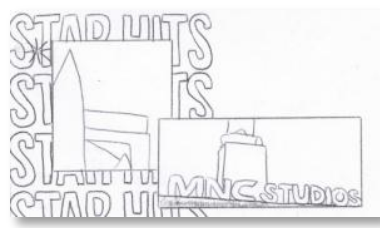

Gambar 6. Scene 5/ Ext/ Day/ Low Angle/Menampilkan Plang Star Media Nusantara dan jalur masuk tower 3

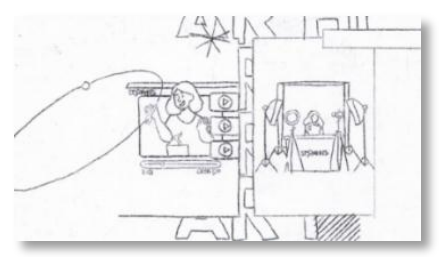

Gambar 8. Scene 7/ Menampilkan ilustrasi menciptakan dan mendistibusikan konten

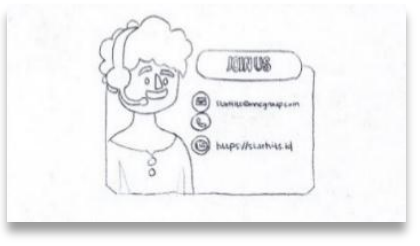

Gambar 10. Scene 9/ Menampilkan animasi Text Join Us ( Email: StarHits@mncgroup.com, Website: https://starhits.id, Phone: (+62)21 5366-1736

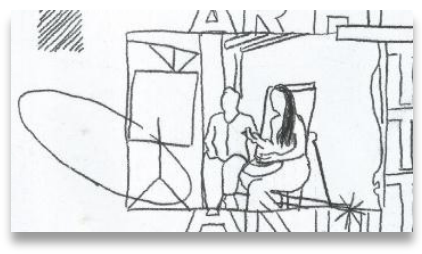

Gambar 5. Scene 4/ Int/ Day/Long Shot/ Menampilkan Studio StarHits

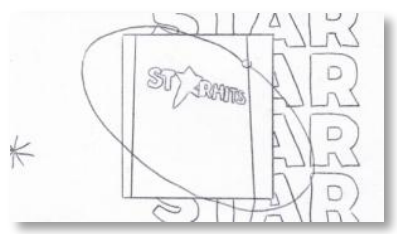

Gambar 7. Scene 6/ Int/ Day/Medium Shoot/Plang StarHits

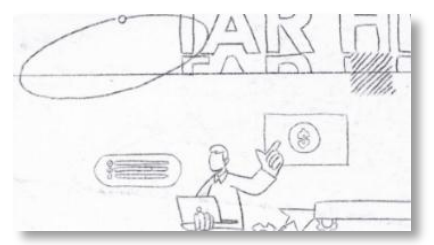

Gambar 9. INT/ Scene 8/ Menampilkan ilustrasi memonetisasi

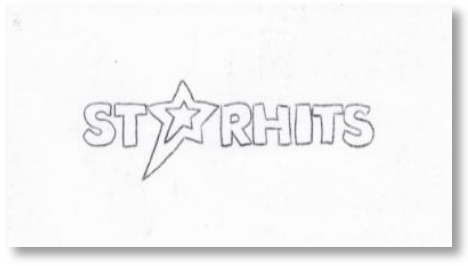

Gambar 11. Scene 10/ Bumper penutup

5. Script Writing

Script Writing adalah sebuah naskah dari masing-masing scene berupa gagasan cerita yang bertujuan untuk memudahkan dalam proses editing.

Tabel 1. Script Writing

\begin{tabular}{|c|l|l|}
\hline No. & \multicolumn{1}{|c|}{ Visual } & \multicolumn{1}{c|}{ Audio } \\
\hline 1 & Bumper StarHits & Music \\
\hline 2 & $\begin{array}{l}\text { Footage Pintu masuk MNC Studio } \\
\text { (Patung Burung dan Tower 3) }\end{array}$ & $\begin{array}{l}\text { Berdiri sejak tahun 2017/ StarHits } \\
\text { merupakan bisnis media }\end{array}$ \\
\hline
\end{tabular}




\begin{tabular}{|c|l|l|}
3 & $\begin{array}{l}\text { Menampilkan Plang Star Media } \\
\text { Nusantara }\end{array}$ & $\begin{array}{l}\text { digital yang bernaung di bawah Star } \\
\text { Media Nusantara/ yang dimana } \\
\text { perusahaan tersebut }\end{array}$ \\
\hline 4 & Menampilkan footage Studio StarHits & $\begin{array}{l}\text { adalah talent management terbesar di } \\
\text { indonesia yang termasuk bagian }\end{array}$ \\
\hline 5 & $\begin{array}{l}\text { Menampilkan footage Plang MNC } \\
\text { Studio dan Gedung Tower 1 }\end{array}$ & dari MNC Group// \\
\hline 6 & Menampilkan footage Plang StarHits & $\begin{array}{l}\text { StarHits sendiri adalah perusahan } \\
\text { Multi Channel Network yang } \\
\text { menyediakan }\end{array}$ \\
\hline 7 & $\begin{array}{l}\text { Menampilkan ilustrasi menciptakan } \\
\text { dan mendistibusikan konten }\end{array}$ & $\begin{array}{l}\text { layanan dalam menciptakan/ } \\
\text { Mendistribusikan/ }\end{array}$ \\
\hline 8 & Menampilkan ilustrasi memonetisasi & $\begin{array}{l}\text { mengelola/ hingga memonetisasi } \\
\text { konten// }\end{array}$ \\
\hline 9 & $\begin{array}{l}\text { Menampilkan Text Join Us (Email: } \\
\text { StarHits@mncgroup.com, Website: } \\
\text { https://starhits.id, Phone: }(+62) 21\end{array}$ & \multicolumn{1}{|c|}{ Music } \\
\hline $5366-1736$ & $\begin{array}{l}\text { Menampilkan Bumper penutup } \\
\text { StarHits }\end{array}$ & \multicolumn{1}{|c|}{ Music } \\
\hline
\end{tabular}

\section{Rundown}

Urutan sebuah cerita disertai dengan rancangan durasi waktu.

Tabel 2. Rundown

\begin{tabular}{|c|c|c|c|c|l|}
\hline No. & Scene & Location & Duration & INT/EXT & \multicolumn{1}{|c|}{ Description } \\
\hline 1 & 2 & $\begin{array}{c}\text { Pintu masuk } \\
\text { MNC Studio }\end{array}$ & Ext & $\begin{array}{c}\text { 00:00:07- } \\
\text { 00:00:12 }\end{array}$ & $\begin{array}{l}\text { Menampilkan footage } \\
\text { Pintu masuk MNC } \\
\text { Studio (Patung Burung } \\
\text { dan Tower 3) }\end{array}$ \\
\hline 2 & 3 & $\begin{array}{c}\text { Gedung Tower } \\
1\end{array}$ & Ext & $\begin{array}{c}00: 00: 13- \\
00: 00: 18\end{array}$ & $\begin{array}{l}\text { Menampilkan Plang } \\
\text { Star Media Nusantara }\end{array}$ \\
\hline 3 & 5 & $\begin{array}{c}\text { Plang MNC } \\
\text { Studio Tower 1 }\end{array}$ & Ext & $\begin{array}{l}00: 00: 23 \\
00: 00: 25\end{array}$ & $\begin{array}{l}\text { Menampilkan footage } \\
\text { Plang MNC Studio } \\
\text { dan Gedung Tower } 1\end{array}$ \\
\hline 4 & 6 & $\begin{array}{c}\text { Tower 2 Lantai } \\
2\end{array}$ & Int & $\begin{array}{c}00: 00: 26 \\
00: 00: 29\end{array}$ & $\begin{array}{l}\text { Menampilkan footage } \\
\text { Plang StarHits }\end{array}$ \\
\hline 5 & 4 & Studio StarHits & Int & $00: 00: 19-$ & $\begin{array}{l}\text { Menampilkan Studio } \\
\text { StarHits }\end{array}$ \\
\hline
\end{tabular}

7. Crew 
Print ISSN: 2723-1992

Online ISSN: 2723-200X

Tabel 3. Susunan Crew

\begin{tabular}{|l|c|c|}
\hline No. & Jabatan & Nama \\
\hline 1. & Sutradara & Mohamad Faisal Abdillah \\
\hline 2. & Kameramen & Mohamad Faisal Abdillah \\
\hline 3. & Asisten kameramen & Abizar Al Ghiffari \\
\hline 4. & Editor & Mohamad Faisal Abdillah \\
\hline 5. & Penulis Naskah & Mohamad Faisal Abdillah \\
\hline 6. & Pengisi Suara & Ajeng Dinanti \\
\hline 7. & Pilot Drone & Budi Sutiyono \\
\hline
\end{tabular}

8. Time schedule

Time Schedule merupakan sebuah planing sebelum melakukan proses produksi media secara keseluruhan sesuai jangka waktu yang telah di rencanakan. Time schedule media video profile StarHits yaitu sebagai berikut

Tabel 4. Time Schedule

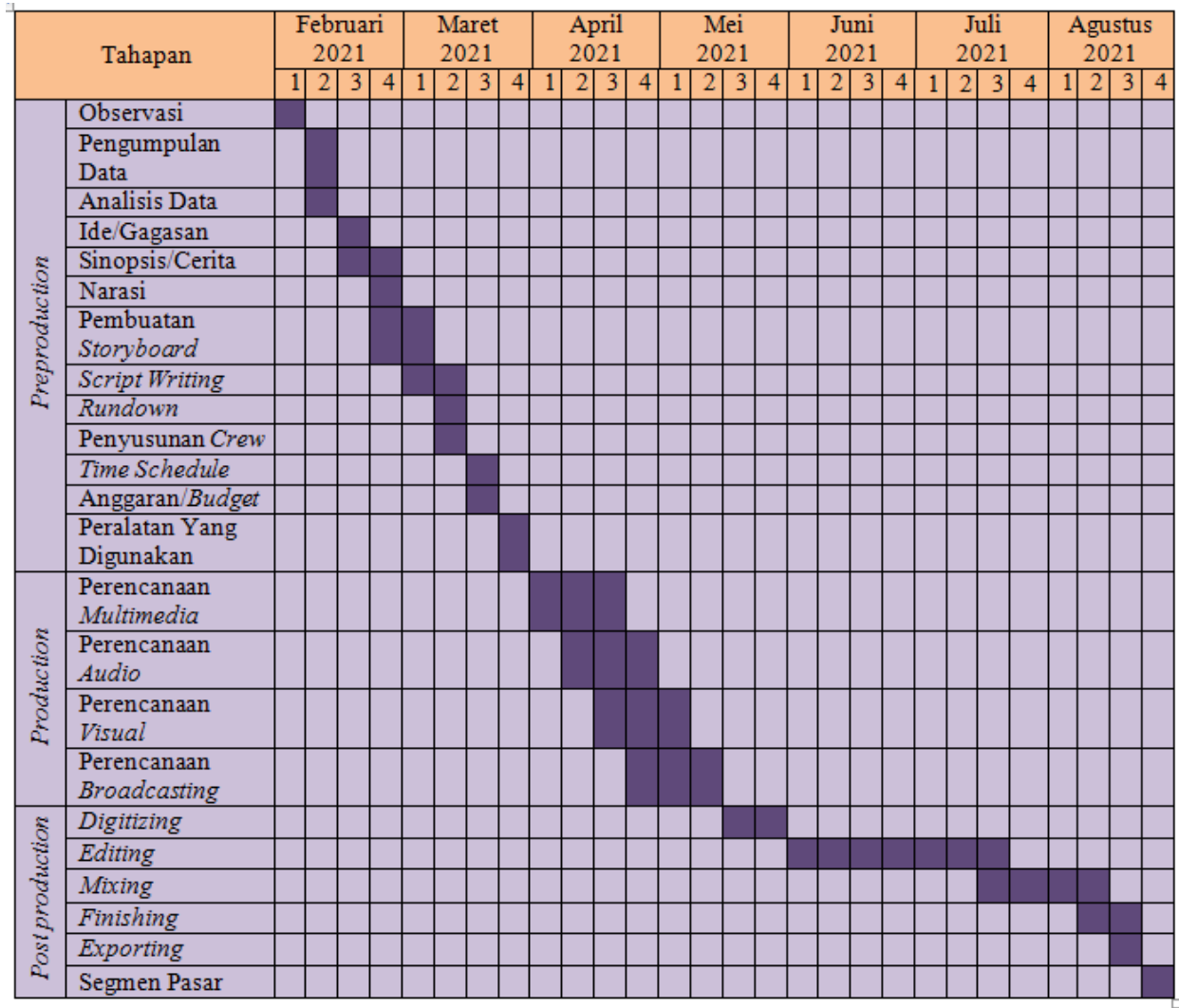

9. Budget

Budget yaitu biaya yang dibutuhkan selama proses prembuatan video profile StarHits Jakarta. 
Tabel 5. Anggaran/Budget

\begin{tabular}{|c|c|c|c|c|c|}
\hline No & Alat Produksi & Ket & Hari & Jumlah & Biaya Produksi \\
\hline 1. & Survey Lokasi & - & 5 & - & $\begin{array}{c}@ \text { Rp. } 50.000 \\
\text { Rp. } 50.000 \times 5 \text { Hari } \\
=\text { Rp. } 250.000\end{array}$ \\
\hline 2. & $\begin{array}{c}\text { Kamera Sony } \\
\text { A6000 }\end{array}$ & Sewa & 2 & 1 & $\begin{array}{l}\quad @ \text { Rp. } 200.000 \\
\text { Rp. } 200.000 \times 2 \text { Hari } \\
=\text { Rp. } 400.000\end{array}$ \\
\hline 3. & $\begin{array}{c}\text { SanDisk Extreme } \\
\text { PRO SDXC UHS-I } \\
\text { 64GB SD Memory } \\
\text { Card }\end{array}$ & Sewa & 2 & 1 & $\begin{array}{l}\quad @ \text { Rp. } 75.000 \\
\text { Rp. } 75.000 \times 2 \text { Hari } \\
=\text { Rp. } 150.000\end{array}$ \\
\hline 4. & Adapter Micro SD & Milik Pribadi & 1 & 1 & - \\
\hline 5. & $\begin{array}{l}\text { Flash Disk Sandisk } \\
\text { Ultra Flair Usb } 3.0 \\
64 G B\end{array}$ & Milik Pribadi & - & 1 & - \\
\hline 6. & $\begin{array}{c}\text { Laptop lenovo } \\
\text { S340 }\end{array}$ & Milik Pribadi & - & 1 & - \\
\hline 7. & Zhiyun Crane M2 & Sewa & 2 & 1 & $\begin{array}{l}\text { @ Rp. } 150.000 \\
\text { Rp. } 150.000 \text { x } 2 \text { Hari } \\
=\text { Rp. } 300.000\end{array}$ \\
\hline 8. & $\begin{array}{c}\text { Dji Mavic mini } \\
\text { Drone }\end{array}$ & Sewa & 1 & 1 & @Rp. 350.000 \\
\hline 9. & Sigma $30 \mathrm{~mm} f 2.8$ & Sewa & 2 & 1 & $\begin{array}{l}\text { @ Rp. } 65.000 \\
\text { Rp. } 65.000 \times 2 \text { hari = } \\
\text { Rp. } 130.000\end{array}$ \\
\hline 10. & $\begin{array}{l}\text { DVD }+ \text { Label }+ \\
\quad \text { Casing }\end{array}$ & Beli & - & 3 & $\begin{array}{c}@ \text { Rp. } 15.000 \\
\text { Rp. } 15.000 \times 3=R p . \\
45.000\end{array}$ \\
\hline 11. & $\begin{array}{c}\text { Transportasi Motor } \\
\text { dan Bensin }\end{array}$ & Beli & 1 & 2 hari & $\begin{array}{c}@ \text { Rp. } 60.000 \\
\text { Rp. } 60.000 \times 2 \text { Hari } \\
=\text { Rp. } 120.000\end{array}$ \\
\hline 12. & Voice Over & Sewa & - & 1 & @ Rp. 350.000 \\
\hline 13. & Konsumsi & Beli & 3 & 3 Orang & $\begin{array}{c}\text { @Rp.35.000 } \\
35.000 \times 3=\text { Rp. } \\
105.000 \\
\text { Rp. } 105.000 \times 3 \text { Hari } \\
=\text { Rp. } 315.000\end{array}$ \\
\hline \multicolumn{5}{|c|}{ Total } & Rp. 2.410.000 \\
\hline
\end{tabular}

10. Peralatan

Dalam proses pembuatan video profile ini alat-alat yang dibutuhkan yaitu, Kamera Sony A6000, SanDisk Extreme PRO SDXC UHS-I 64GB SD Memory Card, FlashDisk Sandisk Ultra Flair Usb 3.0 64GB, Laptop lenovo S340, Zhiyun Crane M2, Dji Mavic Mini, Sigma 30mm f2.8, DVD.

\subsection{Production}

Production adalah proses shooting yang sudah direncanakan dan juga sudah mempersiapkan seluruh gambar yang dibutuhkan dalam tahap sebelumnya. Proses 
Print ISSN: 2723-1992

Online ISSN: 2723-200X

production terdapat 4 tahapan yaitu perencanaan multimedia, perencanaan audio, perencanaan visual dan perencanaan broadcasting.

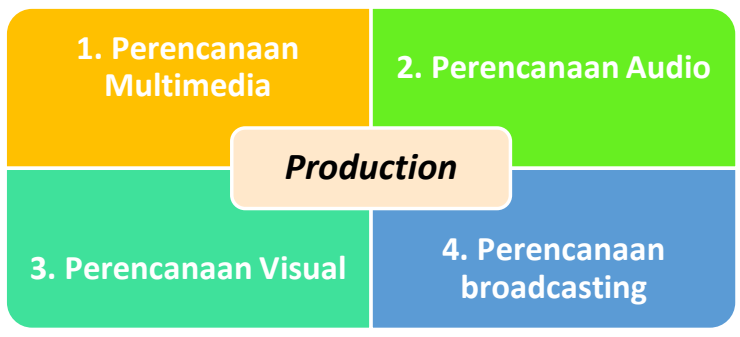

Gambar 12. Production

\section{Program Visual}

Bentuk visualisasi media video profile StarHits :
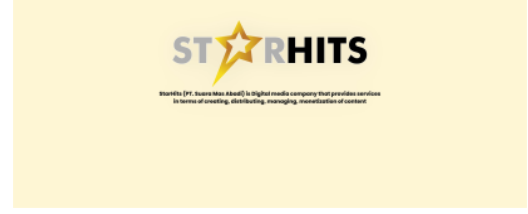

Gambar 13. Scene 1/ Bumper Logo StarHits

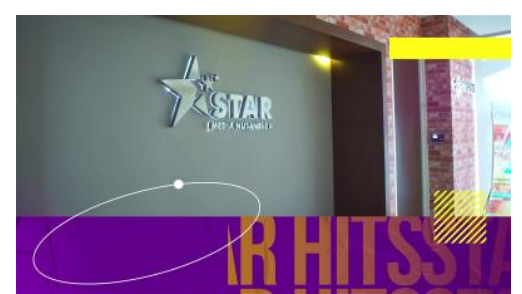

Gambar 15. Scene 3/ Int/ Day/ Long Shot/ Plang Star Media Nusantara

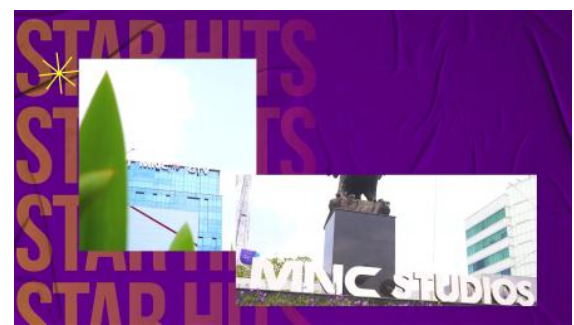

Gambar 17. Scene 5/ Ext/ Day/ Low Angle/Menampilkan footage Plang MNC Studio dan Gedung Tower 1

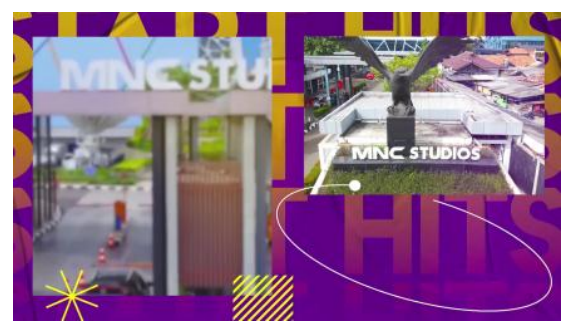

Gambar 14. Scene 2/ Ext/Day / Eye level drone/ Menampilkan footage Pintu masuk MNC Studio (Patung Burung dan Tower 3)

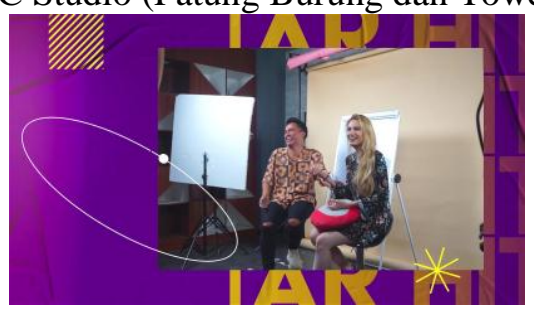

Gambar 16. Scene 4/ Int/ Day/Long Shot/ Menampilkan Studio StarHits

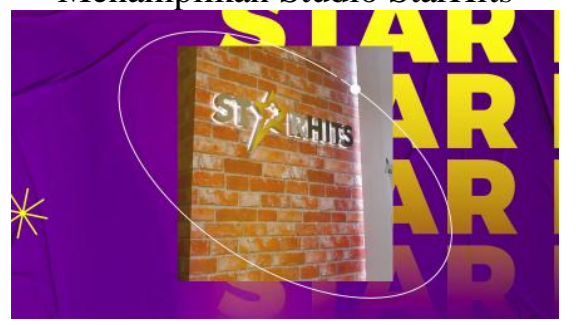

Gambar 18. Scene 6/Int/ Day/Medium Shoot/Plang StarHits 
Print ISSN: 2723-1992

Online ISSN: 2723-200X

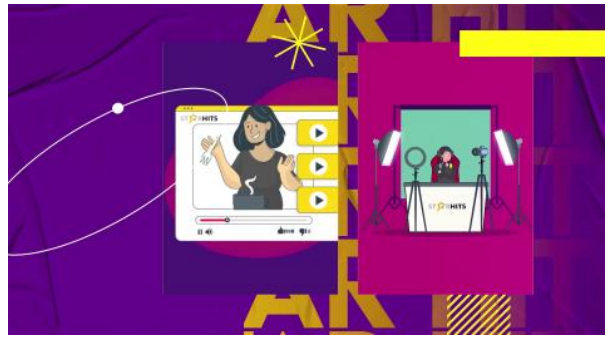

Gambar 19. Scene 7/ Menampilkan ilustrasi menciptakan dan mendistibusikan konten

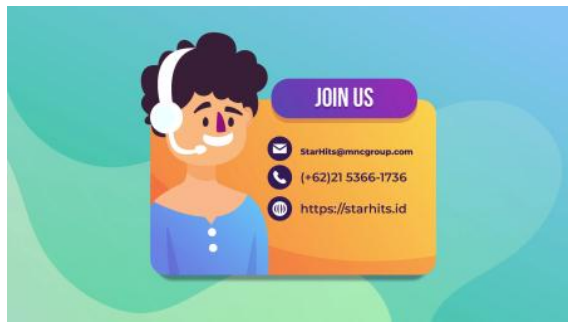

Gambar 21. scene 9/ Menampilkan animasi

Text Join Us

(Email:StarHits@mncgroup.com,

Website: https://starhits.id, Phone:

$$
\text { (+62)21 5366-1736 }
$$

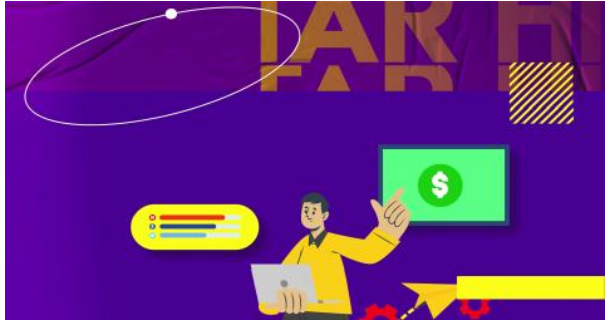

Gambar 20. Scene 8/ Menampilkan ilustrasi memonetisasi

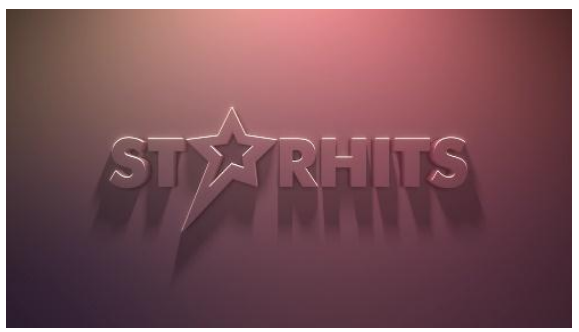

Gambar 22. scene 10/ Bumper penutup

\subsection{Post Production}

Post production merupakan proses terakhir dari tahap pre production dan production yang sudah dirancang dalam storyboard. Tahapan ini membutuhkan beberapa perangkat yang mampu menjalankan software untuk kebutuhan editing sehingga menjadi hasil finishing video. Berikut ini adalah langkah - langkah dalam tahap production meliputi: digitizing, editing, mixing, finishing, exporting dan segmen pasar.

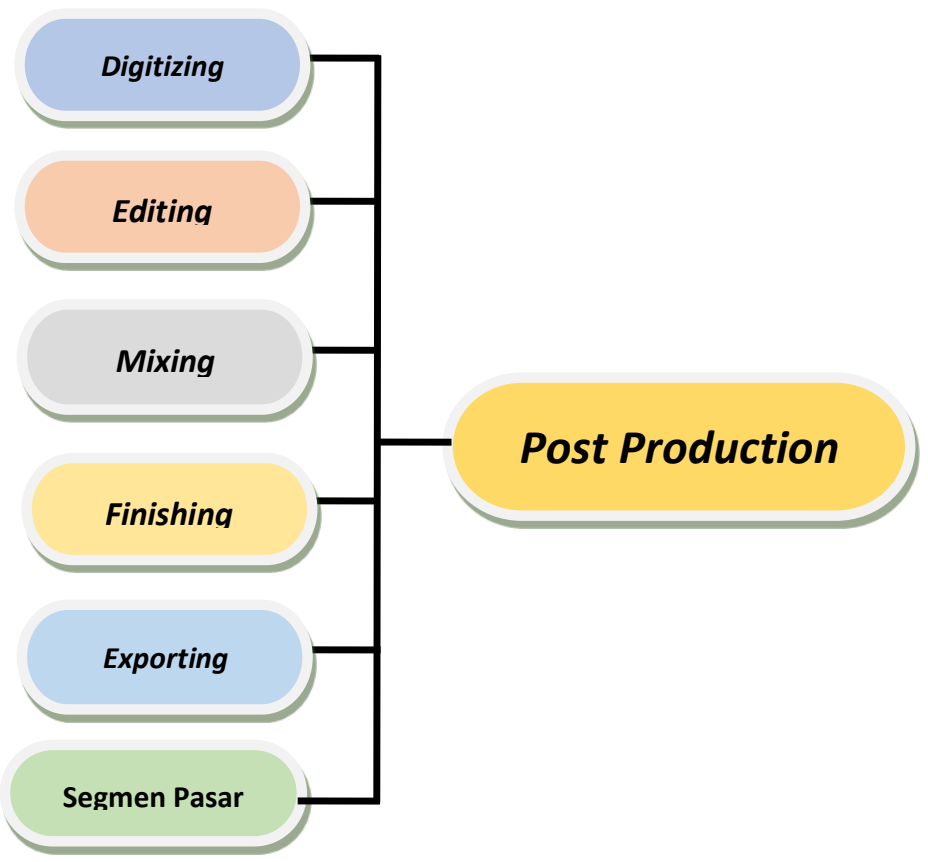

Gambar 23. Post Production 
1. Digitizing

Tahapan Digitizing adalah tahap pemindahan data dari hasil proses shooting untuk dimasukan ke dalam proses editing.

2. Editing

Tahapan editing adalah tahap setelah digittizing untuk melakukan proses editing dari gambaran yang ada di storyboard dan dituangkan ke dalam software editing.

3. Mixing

Mixing merupakan tahapan untuk menggabungkan dari beberapa gambar, backsound, sound effect dan voice over kedalam software editing

4. Finishing

Pada tahapan finishing editor harus memperhatikan kembali dari keseluruhan video yang sudah digabungkan dari video, gambar, suara pada setiap adegan.

5. Exporting

Tahapan terakhir dari hasil pembuatan video yang sesuai dengan script writing lalu bisa di exporting menggunakan software editing.

6. Segmen Pasar

Dalam tahap ini, diharapkan media video profile StarHits Jakarta bisa menjangkau ke seluruh Indonesia maupun Internasional yang membutuhkan jasa media digital, yang menyediakan layanan, dalam hal menciptakan, mendistribusikan, mengelola, hingga monetisasi konten. Melalui media ini dapat lebih dikenal publik serta dapat membantu para calon creator dan creator corporate yang ingin bergabung, sehingga dapat mencapai target StarHits yang diinginkan.

\section{KESIMPULAN}

Berdasarkan dari hasil penelitian yang dilakukan di StarHits (Suara Mas Abadi) terdapat beberapa kesimpulan yaitu dengan melalui konsep video profile yang kreatif sehingga dapat memberikan Informasi yang akurat, jelas, dan update sesuai perkembangan perusahaan saat ini, dimana terdapat informasi mengenai Profil singkat Perusahaan, Service and Benefit, Platform social media StarHits, Achievement, Creator, Creator unit MNC, Portofolio StarHits. Sehingga dapat memudahkan para creator dan creator corporate yang ingin mengetahui informasi dan bekerjasama dengan perusahaan.

\section{SARAN}

Dengan adanya hasil media video profile ini disarankan kepada StarHits (Suara Mas Abadi) untuk mengembangkan video profile ini sebagai sarana promosi, dengan konsep, tema dan jalan cerita yang lebih menarik dan kreatif dengan menggunakan effect visual atau animasi $3 D$, yang disesuaikan dengan kebutuhan perusahaan. Serta memperbaharui informasi pada video profile ini, setiap 2 tahun sekali, agar creator dan creator corporate yang bekerjasama mendapatkan informasi terbaru, sesuai dengan perkembangan perusahaan. 


\section{DAFTAR PUSTAKA}

[1] Ellysinta, Vivia, 2021, Pembuatan Video Profile Sistem Informasi Untuk Profil Lulusan Video Game Developer Dengan tema Retro, Batam: Universitas Internasional Batam, National Conference For Community Service Project, ISSN: 2714-8599, Vol.3, No.1: 1159.

[2] Syahputra, Rizki, 2019, Strategi Pemasaran Dalam Alquran Tentang Promosi Penjualan, Sumatera Utara: Sekolah Tinggi Ilmu Ekonomi (STIE), Jurnal ECOBISMA, ISSN: 2620-3391, Vol.6, No.2: 83.

[3] Hidayat, Riyan, Hendri Gunawan dan Diki Susandi, 2019, Pembuatan Video Profil Perusahaan Berbasis Animasi 3D di PT. Krakatau Insan Mandiri, Serang: Universitas Serang Raya, Jurnal Sistem Informasi dan Informatika, ISSN: 26226375, Vol.2, No.1: 64-80.

[4] Jasmine, Aisyah dan Redito Benaya Loen, 2020, Penggunaan Video Company Profile Sebagai Sarana Informasi dan Meningkatkan Promosi Pada PT Avoir Industry, Jakarta: LSPR Communication \& Business Institute, JTIM: Jurnal Teknologi Informasi dan Multimedia, ISSN: 2684-9151, Vol.2, No.2: 125-132.

[5] Wibowo, Tony dan Jerremy Alexander, 2021, Perancangan dan Pembuatan Video Company Profile PT. Batam Indonesia Gemilang, Batam: Universitas Internasional Batam, Conference on Business, Social Sciences and Technology, ISSN: 28085485, Vol.1, No.1: 711-718.

[6] Rustiana, Deden, Ferry Sudarto dan Al Marwan, 2018, Video Profile Contact Center 121 Pada PT. KAI (PERSERO), Tangerang: STMIK Raharja Tangerang, Journal CICES, ISSN: 2356-5195, Vol.4, No.2: 138-146.

[7] Pratama, Muhamad Adam dan Artyasto Jatisidi, 2021, Perancangan Video Company Profile PT. Dian Permata Omega Sebagai Media Promosi, Jakarta: Universitas Budi Luhur, Jurnal Online Mahasiswa Fakultas Ilmu Komunikasi, ISSN: 2579-7441, Vol.5, No.2. 